\section{Commentary: Surgical treatment of atrial fibrillation at the time of cardiac surgery: Just do it}

\author{
Kevin Hodges, MD, Daniel Burns, MD, \\ A. Marc Gillinov, MD, and Rakesh Suri, MD, DPhil
}

Almeida and colleagues ${ }^{1}$ were tasked with answering a question: What is the best minimally invasive mitral valve operation ${ }^{1}$ In arguing in favor of a robotic approach, the authors highlight the robotic platform's articulating instruments, dynamic left atrial retractor, and 3-dimensional camera, which provide clear advantages over a traditional right thoracotomy approach. These features give expert mitral surgeons access to the entire toolbox of mitral repair techniques, such that essentially any degenerative mitral valve repair could be repaired with a robotic approach. The authors also cite several large series that demonstrate the safety, efficacy, and durability of robotic mitral valve repair. With the caveat that robotic mitral surgery is not right for every program, these are compelling arguments for the superiority of robotics over other minimally invasive mitral approaches.

That being said, the question: What is the best minimally invasive mitral valve operation? is fundamentally misguided. Just as each mitral valve repair technique must be used in an appropriate valve to achieve a perfect repair, minimally invasive surgical approaches need to be used in carefully selected patients to achieve perfect outcomes.

From the Department of Thoracic and Cardiovascular Surgery, Cleveland Clinic, Cleveland, Ohio.

Disclosures: Dr Hodges is a consult for AtriCure; Dr Burns is a consultant for Medtronic; and Dr Gillinov is a consultant for Edwards, Medtronic, Cryolife, Abbott, ClearFlow, and AtriCure. The other author reported no conflicts of interest.

The Journal policy requires editors and reviewers to disclose conflicts of interest and to decline handling or reviewing manuscripts for which they may have a conflict of interest. The editors and reviewers of this article have no conflicts of interest.

Received for publication Oct 12, 2021; revisions received Oct 12, 2021; accepted for publication Oct 12, 2021; available ahead of print Oct 18, 2021.

Address for reprints: Rakesh Suri, MD, DPhil, Department of Thoracic and Cardiovascular Surgery, Cleveland Clinic, 9500 Euclid Ave, Suite J4-1, Cleveland, OH 44195 (E-mail: surir@ccf.org).

JTCVS Techniques 2021;10:82-3

2666-2507

Copyright (C) 2021 The Author(s). Published by Elsevier Inc. on behalf of The American Association for Thoracic Surgery. This is an open access article under the CC BY-NC-ND license (http://creativecommons.org/licenses/by-nc-nd/4.0/).

https://doi.org/10.1016/j.xjtc.2021.10.018

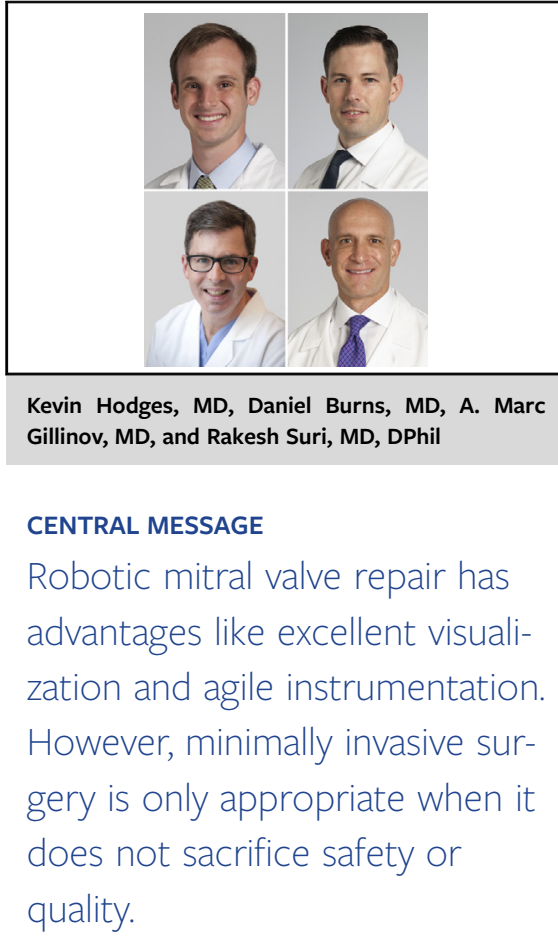

It is our philosophy that minimally invasive surgery is only appropriate when it can be offered without sacrificing safety or quality. We have adopted a conservative screening algorithm, which we use to counsel patients about the most appropriate, data-driven approach for each patient's anatomy and physiology. ${ }^{2}$ Patients with greater-than-mild aortic regurgitation, left ventricular dysfunction, or pulmonary hypertension are offered open surgery to optimize myocardial protection through antegrade and retrograde cardioplegia. Patients with more-than-minimal mitral annular calcification are offered open surgery in the event that extensive debridement and reconstruction of the atrioventricular grove is required. Patients with significant aortoilliac calcification are offered open surgery because of the risk of stroke with femoral cannulation and retrograde perfusion of the descending aorta, and patients with small-caliber femoral arteries are offered open surgery because of the risk of distal limb complications. In a series of 1000 patients with isolated degenerative mitral valve disease, this algorithm qualified $60 \%$ of patients for robotic surgery. There were no mortalities in the robotic or sternotomy groups, and the rates of stroke were similar $(0.5 \%$ for robotic and $1.0 \%$ for sternotomy). ${ }^{2}$

We do find that many patients are referred to our center specifically for robotic mitral valve surgery, and many are 
offered open surgery for the reasons stated above. In these patients, we offer a hemisternotomy approach, with a $J$-shaped incision in the right fifth intercostal space. This approach, performed through a $10-\mathrm{cm}$ or smaller skin incision, is cosmetically superior to a standard sternotomy and allows for central aortic cannulation with direct cannulation of the coronary sinus for delivery of retrograde cardioplegia. A full sternotomy approach is generally reserved for patients with challenging body habitus, including pectus excavatum, patients undergoing concomitant coronary bypass surgery, or patients with severe mitral annular calcification.

It is also essential to discuss the complex value proposition of robotic mitral surgery. In an analysis of 1290 patients undergoing mitral valve surgery at our center, Mihaljevic and colleagues ${ }^{3}$ found that the increased operative cost of robotic mitral surgery-driven by upfront capital investment and maintenance of equipment-was mitigated by lower postoperative hospital costs and greater patient benefit, in terms of shorter recovery and earlier return to work. However, this analysis predicts that the cost of robotic mitral valve surgery is only comparable to conventional approaches in high-volume centers; that is, those with volumes of at least 55 to 100 robotic cases per year. ${ }^{3}$

Robotics have changed the game for mitral valve surgeons, who can now perform the full spectrum of mitral valve repair techniques through very small incisions. However, it is essential that we never compromise patient outcomes for the sake of a minimally invasive approach.

\section{References}

1. Almeida A, Tutungi E, Moten S, Chen Y. Minimally invasive and robotic approaches to mitral valve: robotic is best. J Thorac Cardiovasc Surg Tech. 2021; 10:75-9.

2. Chemtob RA, Wierup P, Mick SL, Javorski MJ, Burns DJP, Blackstone EH, et al. A conservative screening algorithm to determine candidacy for robotic mitral valve surgery. J Thor Cardiovasc Surg. 2020. December 17, 2020 [Epub ahead of print].

3. Mihaljeic T, Koprivanac M, Kelava M, Goodman A, Jarrett C, Williams SJ, et al. Value of robotically assisted surgery for mitral valve disease. JAMA Surg. 2014 149:679-86. 